\title{
Dealing with job applicants
}

SIR-At each rung of the academic ladder, an aspirant can expect to face a search committee. The meeting of applicant with evaluators is likely to be stressful under the best conditions, but the manner in which a search committee operates can make a difference. My recent experience as a job seeker suggests that many committees could use a lesson in etiquette, so, in the absence of a scientific Miss Manners, I propose to offer advice to those who will serve on search committees. 1. Acknowledge receipt of applications. Committee members may feel overwhelmed by hundreds of applications, but should remember that each application represents a large amount of work by the applicant and deserves a polite response. Fifteen per cent of my applications were never acknowledged. After a while, I began to think of the mailbox as a black hole. Upon receipt of an application, a search committee should write to thank the applicant for her or his interest in the job and to provide a tentative timetable for the search.

2. Keep applicants informed. As decisions are reached, applicants should immediately be told if they have been rejected, placed on a short list, or will be interviewed. About 30 per cent of the search committees never told me how I stood in the search, others took as long as 15 months to reply, and some even failed to tell me how a search was concluded after I was interviewed. I suggest that applicants should be contacted every two to three months until their status is final.

3. Don't run a search for a job that doesn't exist. This rule may seem obvious, but 5 per cent of the jobs for which I applied and even one for which I interviewed were cancelled by central administrators. Besides wasting everyone's time, such cancellations suggest to a large number of qualified applicants that your organization is in disarray. If you must cancel a position, a humble letter in which the cancellation is fully explained and blame is accepted can mitigate the damage.

4. The interview should be well-organized and should consider the wishes of the candidate. Most of my interviews were well run and left me with positive impressions, but many interviews do more harm than good. I know candidates who have been stranded at airports and housed at unsafe hotels, who have arrived without appointments or seminars scheduled, who have been taken to restaurants where they could not eat because of dietary needs, and who were neglected for long periods. A committee should appoint a member to set up the candidate's schedule and coordinate the interview, and this person should consult with the candidate before the interview to set up transportation and lodging, to find out if the candidate wishes to speak with particular people or visit particular parts of campus, and to determine if the candidate has other specific needs.

5. Don't insult the candidate. I suppose the few search committees deliberately attempt to insult candidates, so it is surprising how often it happens. It was depressing to be confronted with a department chairperson who would not give straight answers to questions about laboratory space, set-up money, teaching or other questions. These instances were indirectly insulting, but it was much worse to be confronted with racist or sexist remarks. Most of my interviews included at least one meeting where derogatory comments about minority groups or women scientists were made. Imagine my dismay when one male scientist confided that the woman in a scientific couple seldom amounted to much. The man who said this is on a faculty with married scientists, is married to a scientist, knew that I am married to a scientist, knew that I trained with a woman scientist, and knew that my thesis adviser's wife is in the National Academy of Sciences! Other examples were equally bad, and each such statement suggested to me that I would be better off somewhere else. (In retrospect, I should perhaps be grateful that so many people were so guileless as to reveal their true thoughts in a short discussion.)

Why should a search committee bother to follow these suggestions? After all, when you gaze at those hundreds of applications, you may think that it will be no trouble to attract your top choice. Consider, however, that stories of poorly run searches and interviews rapidly circulate among potential job candidates and can make them wary of your department. Consider that, even in the current job market, most people receive more than one job offer so you will probably be competing for your top choice. Finally, consider that many of the people who apply to you will be around for years to come, and could come back to haunt you in unexpected ways. In my experience, search committees that pay attention to etiquette are run in exemplary fashion. and leave everyone involved satisfied that a difficult task has been well perfomed.

JefFrey B. Miller

Division of Oncology, Room M-211,

Stanford University Medical School,

Stanford, California 94305-5306, USA

\section{Spanish science}

SIR-The National Plan for Scientific Research and Technological Development is in the process of being precisely defined in Spain. The government has considerably increased economic support for research, in particular in grants for several priority fields. But there are structural problems that are not being tackled, such as the inadequacy in the national distribution of research centres or the comparatively low salaries or scientists.

The national plan defines objectives according to which grants are available. But there seems to be no plan to provide new positions. The number of scientists in temporary postdoctoral positions both in Spain and abroad is increasing alarmingly. The situation is most acute for those scientists who have worked abroad for many years and want to establish their own research projects upon returning to Spain. Many of them have obtained permanent positions in the Spanish research council (CSIC), but when they want to start working in one of its institutes, little space is available and their access to research funds is severely limited. Scientists returning home are not warmly received by the CSIC and many choose in the end not to return under such conditions.

It seems to me that more scientists and more laboratories should be involved in the development of the national plan. Some time ago, Dr E. Trillas, president of the CSIC, declared in an interview that "one may put obstacles in the way of outstanding scientists, because they will go ahead anyway". This is of course true, but it will not help scientists to become established in Spain.

Juan A. Subirana

Unidad de Quimica Macromolecular,

Escuela Técnica Superior

de Ingenieros Industriales,

Diagonal, 647,

08028 Barcelona, Spain

\section{Who should pay?}

Sir-It seems to me that the essential question about who is paying for new drugs is not "Is it acceptable for patients to fund research indirectly but not acceptable when the direct relationship is apparent?" as suggested by Robert Oldham (Nature 332, 795; 1988) but whether it is an improvement that a patient is charged a large amount of money for treatment, whereas we invented health insurances to share costs that cannot be borne by one person. The answer has to deal not only with ethical aspects but also with the rate of progress that can be made in clinical research using direct or indirect charges. I therefore support Oldham's conclusion that "the question of who pays for clinical research needs broad public debate and openness on the part of all the parties involved in developmental therapeutics". William Den Otter

Pathologisch Instituut,

Pasteurstraat 2,

Utrecht,

The Netherlands 